\title{
Swaps e empresas públicas em Portugal: uma história de poder, cisnes negros e ilusões
}

Swaps and State-Owned Enterprises in Portugal: A Story of Power, Black Swans and Illusions

Swaps et entreprises publiques au Portugal: une histoire de pouvoir, cygnes noirs et illusions

Júlio Lobão

\section{OpenEdition}

\section{Journals}

Edição electrónica

URL: http://journals.openedition.org/rccs/10632

DOI: $10.4000 /$ rccs. 10632

ISSN: 2182-7435

\section{Editora}

Centro de Estudos Sociais da Universidade de Coimbra

Edição impressa

Data de publição: 1 setembro 2020

Paginação: 53-76

ISSN: 0254-1106

\section{Refêrencia eletrónica}

Júlio Lobão, « Swaps e empresas públicas em Portugal: uma história de poder, cisnes negros e ilusões », Revista Crítica de Ciências Sociais [Online], 122 | 2020, posto online no dia 10 setembro 2020, consultado o 15 setembro 2020. URL : http://journals.openedition.org/rccs/10632 ; DOI : https:// doi.org/10.4000/rccs. 10632 


\section{JÚLIO LOBÃO}

\section{Swaps e empresas públicas em Portugal: uma história de poder, cisnes negros e ilusões}

A construção de narrativas é um dos elementos centrais no funcionamento dos mercados financeiros modernos. Neste artigo analisamos as estratégias discursivas de um conjunto de gestores de empresas públicas de Portugal perante uma Comissão Parlamentar de Inquérito. Essa comissão foi criada pela Assembleia da República em 2013 para investigar as perdas verificadas pela celebração de contratos derivados (swaps) nas empresas públicas. Recorrendo a conceitos de várias áreas, entre as quais a sociologia das finanças e a psicologia cognitiva, a nossa análise revela que as condições de incerteza e as ilusões cognitivas dos gestores influenciaram as suas narrativas de racionalização. As relações de poder entre os atores sociais em presença (poderes públicos, bancos, empresas) transparecem igualmente no discurso dos gestores. Nas nossas conclusões evidenciamos as implicações destes fatores para a construção de uma visão mais contextualizada das relações financeiras.

Palavras-chave: empresas públicas; gestão empresarial; incerteza (economia); mercados financeiros; Portugal; relações de poder.

\section{Introdução}

$\mathrm{O}$ uso da retórica constitui um dos elementos centrais no funcionamento dos mercados financeiros modernos. Conforme explica McCloskey (1992), uma larga parcela do tempo dos agentes de mercado é ocupada a construir histórias e a usar metáforas. As vidas dos atores económicos estão permanentemente entrelaçadas em narrativas, e as histórias que ouvem são retrabalhadas para construir a história que os atores contam a si próprios a fim de tornar inteligíveis as suas decisões (Tuckett, 2011).

Neste artigo procedemos à análise das declarações dos gestores de empresas públicas portuguesas perante a Comissão Parlamentar de Inquérito (CPI) à Celebração de Contratos de Gestão de Risco Financeiro por Empresas do Sector Público, criada pelo Parlamento português para investigar as 
circunstâncias que rodearam a contratação de swaps ${ }^{1}$ por parte dessas empresas. As audições dos gestores das empresas decorreram em 2013, quando o valor de mercado das perdas destas entidades nas operações com swaps ultrapassava já os 3000 milhões de euros. As cerca de 4000 páginas de documentação, entre transcrições das audições e elementos entregues à CPI, constituem um manancial de informação precioso para se entender as motivações e racionalizações dos gestores das organizações e foi obtido no sítio da Assembleia da República. ${ }^{2}$

A nossa análise revela que as relações de poder entre acionistas, entidades bancárias e gestores transparecem no discurso destes últimos agentes. Este facto evidencia o carácter eminentemente político das regras de mercado, enquanto normas fortemente influenciadas pela interação entre os atores de mercado e as instituições de poder. As condições de incerteza e os limites ao conhecimento, especialmente sentidos em períodos de crise, estão também patentes nos padrões de autoapresentação e de representação dos gestores empresariais. É nessas condições de incerteza exacerbada que a inserção cognitiva dos gestores - correspondente ao conceito de cognitive embeddedness, na aceção de Zukin e DiMaggio (1990) - se manifesta de forma mais notória.

Ao longo das últimas décadas, a investigação sociológica tem revelado que o estudo de materiais como declarações públicas de gestores, cartas, diários e/ou autobiografias é útil, na medida em que revela de que forma os agentes interpretam as suas próprias ações; permite ainda perceber as regras que estes adotaram e o modo como monitorizaram o seu comportamento e o mundo das transações financeiras. Para a execução do presente artigo, mobilizamos conceitos da sociologia das finanças e da psicologia cognitiva. A análise sociopsicológica das decisões dos clientes bancários está pouco presente na sociologia portuguesa, pelo que com o nosso trabalho contribuimos para suprir essa lacuna. Este artigo insere-se no domínio da sociologia das finanças - ver, por exemplo, Carruthers e Kim (2011) para uma revisão da literatura sobre esta área interdisciplinar - e constitui uma contribuição para a literatura deste campo.

Diversos estudos baseados na análise de conteúdo documental têm sido levados a cabo no campo da sociologia das finanças. Por exemplo,

\footnotetext{
${ }^{1}$ Um swap constitui, em termos gerais, um acordo de troca de fluxos financeiros. Um swap de taxa de juro, como os contratados pelas empresas em questão neste artigo, é um acordo através do qual uma empresa pública e uma entidade bancária acordam trocar os fluxos financeiros referentes ao pagamento dos juros de um empréstimo.

2 Acessível em https://www.parlamento.pt/sites/com/XIILeg/CPICCGRFESP/Paginas/default. aspx (última consulta a 17.07.2020).
} 
Abolafia (2005) examinou as transcrições das reuniões da Reserva Federal dos Estados Unidos da América (EUA). A sua análise revela que, apesar da autoridade monetária dispor de dados quantitativos abundantes e de elevada capacidade de tratamento da informação, as reuniões presenciais entre os seus membros traduzem-se num esforço coletivo de racionalização para criar respostas de política plausíveis. Já Holmes (2009) explorou o conceito de uma "economia de palavras" para desenvolver um trabalho no campo da antropologia económica. O autor mostra que os produtos comunicacionais provenientes dos bancos centrais se revestem de elevada importância ao criar contextos que permitem ultrapassar os limites do que é calculável e mensurável.

A investigação das narrativas elaboradas pelos atores sociais é de especial interesse nos períodos de rutura e de crise. De facto, é nestas ocasiões que frequentemente se expõem os fatores que se revelaram decisivos no desenvolvimento das dinâmicas socioeconómicas. Vários autores têm-se debruçado sobre as narrativas ligadas à crise financeira. Por exemplo, Svetlova (2012) e Rosenhek (2013) examinaram as narrativas de diagnóstico e de explicação da crise de 2007/2008 produzidas por um grupo de bancos comerciais e por algumas das principais autoridades monetárias a nível global. Estes trabalhos sugerem que numa primeira fase o discurso dessas instituições se rigidificou adotando a narrativa das correntes financeiras neoclássicas, com a consequente falta de consideração do papel da incerteza económica. No entanto, numa segunda fase, o discurso revela uma reavaliação significativa, ainda que parcial, das verdades estabelecidas. O nosso estudo contribui igualmente para a literatura acerca das narrativas explicativas da crise financeira de 2007/2008 ao explorar o discurso de racionalização desses eventos por parte de um conjunto de gestores de empresas públicas portuguesas.

Os estudos sociológicos de conteúdo documental não se cingem, é claro, ao discurso produzido pelas autoridades económicas. Por exemplo, Ailon (2012) explorou as estratégias discursivas contidas nos comentários do Wall Street Journal na sequência dos colapsos do fundo LTCM e da empresa Enron. A racionalização dos acontecimentos passou por uma reinterpretação de cariz moral dos comportamentos de assunção de risco. Hasbani e Breton (2013) analisaram as estratégias discursivas contidas nas mensagens dos gestores de uma empresa farmacêutica dirigidas aos seus acionistas. A principal conclusão é a de que, num momento de crise, as narrativas são construídas para restabelecer a legitimidade organizacional aos olhos do público. E ainda mais recentemente, Devlin e Lucey (2016) efetuaram uma análise às comunicações enviadas por um gestor de topo de uma instituição 
bancária aos seus acionistas ao longo de uma década. Aplicando indicadores da área da psicologia clínica, os autores concluem que o dito gestor evidenciou sintomas de narcisismo e de excesso de confiança até ao dealbar da crise financeira de 2007/2008.

Nas secções seguintes exploramos o papel das relações de poder, da incerteza e das ilusões cognitivas no discurso dos gestores das empresas públicas.

\section{Relações de poder}

A atenção dedicada às relações de poder entre os atores em presença é um dos fatores distintivos da sociologia económica face a outras disciplinas sociais. Na verdade, a visão frequentemente adotada pela análise económica assenta na ideia de uma sociedade atomizada e hiperindividualista, pelo que se tende a subvalorizar as dinâmicas de poder. Já na perspetiva sociológica, o poder manifesta-se não apenas num contexto de mercado, mas igualmente num contexto social mais abrangente (Smeltzer e Swedberg, 2005).

Ao longo das últimas décadas, a investigação sociológica tem dedicado atenção à forma como as trocas económicas são afetadas pelas relações de poder entre os atores económicos (indivíduos ou organizações), e entre estes atores e instituições sociais, maxime os atores políticos (Zuckin e DiMaggio, 1990). Uma das principais conclusões é a de que os fatores políticos podem ter um impacto muito significativo nos atores económicos e nos setores por eles constituídos (Baum e Oliver, 1992). Mas as conclusões vão mais além: conforme tem vindo a ser demonstrado, as regras de mercado são políticas por natureza, no sentido de que são a expressão de relações de poder; as próprias regras de mercado são moldadas pela interação entre os atores de mercado e as instituições políticas. As tendências contraditórias da cultura de mercado são mantidas em equilíbrio por instituições que representam diversos grupos de interesse (McGuire e Granovetter, 1999). Em certos casos históricos, as instâncias políticas de poder são até cruciais na criação de instituições financeiras, como no caso da emergência das bolsas de valores (Carruthers, 1996).

Como veremos, a análise da teia de relações de poder entre os diversos atores em presença nas empresas públicas em Portugal é essencial para se entender as decisões tomadas pelos intervenientes. Se se adotar o pressuposto de que os agentes (Estado, empresas públicas, bancos de investimento) atuaram sem restrições de poder, seja ele formal ou fáctico, não é possível compreender as decisões tomadas.

De seguida analisamos as relações de poder entre as empresas públicas e os seus acionistas (o poder público), entre as empresas públicas e as entidades bancárias e, por fim, entre os acionistas e as entidades bancárias. 


\subsection{Empresas públicas e acionistas}

O fator precipitador dos acontecimentos no caso dos swaps pode ser encontrado na relação de poder entre o Estado enquanto acionista e os gestores das empresas públicas. Esse poder manifestou-se, pelo menos, de duas formas. Por um lado, o Estado impôs objetivos às empresas públicas, por exemplo, em termos de investimento a realizar ou de tarifas a cobrar pelos serviços prestados. Por outro lado, o Estado negou às empresas a entrada dos capitais necessários para realizar esses investimentos. A acrescentar a estes fatores deve-se salientar ainda que a inexistência de contratos plurianuais de serviço público, capazes de proporcionar aos gestores um maior horizonte de planeamento de atividades, deixou estes agentes numa situação de incerteza acrescida.

O único resultado possível destes dois tipos de pressão e do estado de incerteza gerado é o aumento do endividamento a assumir pelas empresas. No fundo, o acionista das empresas, ao optar por não dotar as organizações de um nível adequado de capitais próprios, estava a exercer o seu poder para escolher um modelo de financiamento altamente alavancado.

Sendo o Estado o acionista único nas empresas em causa, dificilmente as suas decisões poderiam ser questionadas por outras instâncias de poder. A assimetria de poder entre o Estado e os gestores reflete-se, de forma clara, no sentimento de inevitabilidade expresso por estes agentes ao longo das sessões da CPI. O endividamento era visto como a única saída:

[...] a empresa era conduzida ao endividamento, era levada a endividar-se porque a carga, o peso da dívida da empresa não era refletido no défice do Estado. Portanto, a opção de todos os governos [...] foi esta: [...] quem convidava, digamos, ou instrumentalizava a empresa para um endividamento que era útil ao País era o Estado, mas quem o suportava e refletia nas suas contas era a [empresa] REFER. ${ }^{3}$

A assimetria de poder verificava-se não apenas num domínio factual ou informal. Mesmo no domínio das regras codificadas e com legitimidade reforçada pelas instituições de direito observava-se a subjugação dos interesses da gestão das empresas públicas aos interesses do acionista. Um caso notório reside nas decisões relacionadas com o artigo $35 .^{\circ}$ do Código das Sociedades Comerciais. Segundo este artigo, qualquer empresa em situação de falência técnica, como aquela em que se encontravam todas as empresas sob análise, deveria convocar uma assembleia geral de acionistas

\footnotetext{
3 Ata da audição de 17/09/2013 ao Presidente do Conselho de Administração da REFER (no período de 2005 a 2012), p. 3.
} 
para ultrapassar a situação. Nos casos em causa, a comunicação da situação por parte da empresa não mereceu sequer a resposta do acionista, o que constitui mais uma manifestação flagrante das relações de poder que temos vindo a descrever.

O passo entre uma relação de poder assimétrica como a agora descrita e um princípio de ressentimento e de sentimento de injustiça é muito curto:

Portanto, estas empresas [...] foram confrontadas com problemas gravíssimos de tarifas artificialmente baixas; de indemnizações compensatórias, que nunca foram suficientes; de serviço público que nunca se discutiu o que é que devia ser, nem quanto é que custava e em que condições devia ser prestado; de, em muitos casos, gestão operacional pouco eficiente; e, por último, de um acionista que sempre tratou muito mal as suas empresas. ${ }^{4}$

\subsection{Empresas públicas e entidades bancárias}

As relações de poder não afetam apenas acionistas e gestores. Pelo contrário, existe uma teia de relações que se repercute num outro agente essencial no contexto em análise: as entidades bancárias. O fraco ou inexistente poder negocial dos gestores face ao acionista enfraquecia-os frente aos bancos a quem recorriam para obter crédito. De facto, estas últimas entidades, conscientes de que os gestores a elas se dirigiam "em estado de necessidade", encontravam força negocial para apresentar propostas que, embora sendo desfavoráveis para as empresas, tinham que ser aceites. Efeitos das relações de poder, novamente.

O elevado poder negocial dos bancos face aos gestores das empresas públicas tomou diversas formas. Em primeiro lugar, as instituições bancárias apresentavam, na maioria dos casos, propostas em que aos contratos de financiamento estavam forçosamente associados a contratos de swaps. Dito de outra forma, para ter acesso ao financiamento as empresas tinham que aceitar esse tipo de contratos.

O estado de assimetria de poder negocial é evidente nas declarações dos gestores, que referem que foram "obrigados" a realizar operações de que necessitavam "em absoluto" e que estavam, na prática, perante uma "imposição":

${ }^{4}$ Ata da audição de 04/09/2013 ao Presidente da Carris e do Metropolitano de Lisboa (no período de 2003 a 2013), p. 134. 
[S]e as necessidades de financiamento fossem substancialmente menores, provavelmente a empresa teria conseguido em mercado financiar-se sem que fosse exigida a contratação (repito: exigida) de instrumentos de gestão de risco financeiro. ${ }^{5}$

É um facto que para nós [empresa Metro do Porto] não tínhamos alternativa [à contratação de um empréstimo] [...] sem simultaneamente assinarmos um contrato de derivado. Por isso, era praticamente uma imposição para obtermos financiamento. ${ }^{6}$

Em segundo lugar, a relação de poder manifesta-se pela imposição de índices proprietários por parte dos bancos. Pois, em vários dos casos analisados, os swaps propostos tinham um resultado financeiro associado a índices proprietários das entidades bancárias. Isto significa, por um lado, que quer o valor da taxa de juro a pagar ao banco em resultado dos swaps quer o valor do próprio contrato não podiam ser calculados pelos gestores das empresas. Uma vez que se tratavam de índices que são propriedade dos bancos, as fórmulas de cálculo eram confidenciais e, portanto, não eram disponibilizadas aos clientes. Por outro lado, a contratação de swaps com resultados associados a um índice proprietário dificultava a contratação posterior de outras operações, noutras instituições de crédito, com o objetivo de cobrir os riscos gerados pelos swaps originais. Dito de outra forma, se os gestores das empresas públicas quisessem cobrir, junto de um banco A, o risco associado a um swap baseado num índice proprietário anteriormente contratado junto de um banco B, tal não seria possível. A situação de desvantagem na relação de poder é bem patente na declaração de um dos gestores: "[o]u seja, um swap com um índice proprietário coloca-nos reféns de um banco, obviamente". ${ }^{7}$ A análise de Lépinay (2011) sobre a relação entre os clientes e os bancos coloca-se na perspetiva destas últimas entidades e permite lançar alguma luz sobre a importância da criação e imposição contratual de índices proprietários. A utilização destes índices está longe de ser incidental. Com efeito, os contratos derivados como os swaps são criados precisamente com o propósito de gerar assimetrias entre os bancos e os clientes. A dinâmica de inovação de produtos produz rendas temporárias para a entidade inovadora, a instituição bancária. Verifica-se que os bancos investem fortemente para manter o secretismo das fórmulas e para capitalizar essa

\footnotetext{
${ }^{5}$ Ata da audição de 22/10/2013 ao 2. ${ }^{\circ}$ Diretor Administrativo e Financeiro da Metro do Porto (no período de julho de 2006 a junho de 2011), p. 86.

6 Ata da audição de 10/09/2013 ao Presidente do Conselho de Administração da Metro do Porto (no período de março de 2008 a julho de 2012), p. 120.

7 Ata da audição de 15/10/2013 ao Diretor Financeiro da REFER (no período de de 2003 aagosto de 2012), p. 76.
} 
vantagem face aos seus concorrentes e clientes. Esta ênfase na confidencialidade sugere que esses códigos são considerados como sendo essenciais no sucesso das instituições (ibidem). A disseminação dessas "fórmulas mágicas" colocaria em causa a assimetria existente e limitaria a vantagem competitiva de que os bancos podem usufruir face aos competidores.

Apesar disso, a criação de assimetrias através da constituição de índices proprietários tem os seus limites. A elaboração de fórmulas exclusivas limita a comunicação entre as partes do negócio (os bancos e os seus clientes) pelo que podem dificultar a adoção de uma linguagem comum. Existe, assim, uma tensão que leva a que o cenário se situe algures entre dois polos opostos: i) um estado em que as fórmulas são do conhecimento de todos os agentes, em que a comunicação entre as partes é fluida porque assenta numa base comum de conhecimento e em que nenhum banco tem vantagens particulares sobre os restantes e ii) um outro estado em que a assimetria é exacerbada pelo facto de os bancos fazerem uso de códigos exclusivos - e em que alguns conseguem inclusivamente vantagens informacionais face a concorrentes e clientes.

Quando o poder negocial dos clientes é muito reduzido, como no caso em apreço, a assimetria na relação de poder leva a que a negociação se situe mais próxima do segundo polo a que fizemos referência.

\subsection{Estado (acionista) e entidades bancárias}

As relações de poder que se estabeleceram entre o acionista das empresas públicas e as entidades bancárias constituem um derradeiro elemento a ter em conta. Quando o acionista se apercebeu da magnitude do problema, decidiu chamar a si a responsabilidade de renegociar os contratos de swaps, de forma centralizada, com as entidades bancárias. Essa decisão, só por si, reforçou o poder do lado comprador dos swaps. O Estado tem mais recursos negociais e maior poder de persuasão face a entidades que, por operarem num setor fortemente regulado, têm interesse em manter boas relações com os poderes públicos.

Embora a parte compradora dos swaps tenha passado a dispor de maior poder negocial, é necessário ter em conta que a relação assimétrica de poder entre empresas públicas e entidades bancárias, a que nos referimos na secção anterior, se transferiu, em parte, para a nova relação negocial. Isto porque as entidades bancárias impuseram às empresas públicas a condição contratual das disputas, em caso de litígio judicial, terem que ser dirimidas nos tribunais do Reino Unido, de acordo com a jurisprudência desses tribunais.

Ora, sabendo que a jurisprudência do Reino Unido atribui uma importância crucial à componente literal dos contratos, entendida como exercício 
da livre vontade das partes, ao mesmo tempo que tende a menorizar a importância das circunstâncias supervenientes aos contratos, é fácil perceber que esta condição reforçou o poder negocial das instituições bancárias.

A importância que uma das partes atribuiu à interpretação dada por um dos centros financeiros internacionais aos contratos não é mais do que a constatação de que os conceitos definidos pelos expoentes da globalização financeira - em particular os centros financeiros de Nova Iorque e da city de Londres - são os que tendem a legitimar as práticas financeiras. Tal reforça a ideia defendida por diversos juristas (e.g., Pistor, 2013) de que o sistema financeiro tem uma estrutura profundamente hierárquica, havendo diferenças significativas entre o "centro" e as "periferias".

Considerando os diversos elementos de poder em causa, podemos presumir que estamos perante uma relação de poder relativamente mais simétrica entre o Estado português e as entidades bancárias.

\section{Incerteza, "cisnes negros" e falhas de imaginação}

A incerteza é uma das marcas mais relevantes das economias contemporâneas. Num ambiente caracterizado por escolhas rotineiras, o passado poderia ser considerado como uma fonte de informação confiável para prever o futuro. No entanto, não são assim as economias modernas. Os papéis centrais desempenhados pela criatividade e pela inovação nos processos económicos conjugam-se com a natureza singular da passagem do tempo para criar uma realidade em que o presente e o futuro são transmutáveis e estão essencialmente em aberto - independentemente do nível de racionalidade que se impute aos agentes económicos, o curso dos acontecimentos permanece imprevisível (Dunn, 2001). Embora o conceito de incerteza possa albergar interpretações diversas (e.g., Dow, 2012), é interessante notar que o assunto está a ser objeto de renovado interesse por parte dos sociólogos (e.g., Beckert, 1996; Swedberg, 2010).

A incerteza e os limites à previsão do futuro são especialmente notórios no campo das finanças e, ainda mais, em períodos de crise. A este respeito, tem sido reconhecido o carácter particular dos mercados financeiros. Ao contrário dos restantes mercados, os mercados financeiros não dizem respeito à produção e distribuição de bens; relacionam-se, isso sim, com a transação de instrumentos financeiros que não foram concebidos para serem consumidos. Nesta medida, os mercados financeiros podem ser considerados como uma "economia de segundo nível", derivada da chamada "economia real"; nos mercados financeiros, os "bens" são contratos (ações, futuros, opções, etc.) mais ou menos distantes da "economia real", que definem os fluxos financeiros entre as partes de uma transação, e que circulam entre 
os investidores. A inovação financeira, ao gerar produtos complexos apenas conectados indiretamente com a produção de bens, cria níveis adicionais de incerteza. Tendem a produzir-se sucessivas camadas de complexidade que afastam progressivamente os resultados gerados por esses instrumentos da realidade dos seus ativos subjacentes (Pixley, 2014). Um dos sintomas mais evidentes destes desenvolvimentos pode ser encontrado no crescimento exponencial dos contratos derivados (Arnoldi, 2004).

A esta evolução dos mercados financeiros, juntaram-se os efeitos da crise financeira. Existe abundante literatura que indica que em períodos de crise financeira, a incerteza fundamental das economias é exacerbada. A volatilidade dos mercados financeiros e do crescimento económico tende a aumentar significativamente durante as recessões (Bryan et al., 2012).

Neste contexto de incerteza, os decisores não têm instrumentos fiáveis que os orientem (Pixley, 2014). A sua experiência de vida e memória histórica constitui uma das poucas pistas de que se podem socorrer. No entanto, é precisamente neste campo que se podem gerar os maiores perigos.

A natureza rara de eventos com a magnitude da crise financeira de 2007/2008 sugere que os atores sociais podem ser vitimados por uma variante específica de incerteza, proposta por Nassim Taleb (2010) e designada por "cisne negro" (black swan). Um "cisne negro" é um evento relevante que é tão raro que é extremamente improvável que tenha sido observado pelos agentes em presença num dado momento no mercado. Como os agentes não estão conscientes da possibilidade de ocorrência de eventos desse tipo, tendem a ficar excessivamente confiantes e a adotar comportamentos que contribuem para a fragilidade do sistema financeiro. A adoção de comportamentos especulativos quando se esperaria, em teoria, observar apenas a cobertura de riscos preexistentes, é um dos sintomas desse excesso de confiança:

[...] a [empresa] REFER pagaria uma taxa de juro variável associada à coroa sueca e receberia uma taxa de juro variável indexada à Euribor, verificamos que o que este swap, no fundo, faz é especular na diferença entre as duas taxas, e não cobrir risco. ${ }^{8}$

À questão do Deputado João Galamba: "Se nós utilizamos um swap não para eliminar risco, mas para otimizar os custos de financiamento, nós só podemos reduzir o custo de financiamento em troca de mais risco. Ou estou enganado?", respondeu o gestor Dr. Alberto Diogo: "É verdade. É mais risco.".

\footnotetext{
8 Ata da audição de 17/09/2013 ao Presidente do Conselho de Administração da REFER (no período de 2005 a 2012), p. 15.

9 Ata da audição de 15/10/2013 ao Diretor Financeiro da REFER (no período de outubro de 2003 a agosto de 2012), p. 37.
} 
A crença de que se tinha capacidade para acompanhar e prever as tendências de mercado levou a que em várias empresas públicas se tivessem adotado práticas de gestão ativa da carteira de swaps, com o consequente acréscimo de riscos.

Quando um "cisne negro" ocorre, os agentes tendem a vivenciá-lo como um evento singular, inédito, dadas as suas óbvias limitações de memória histórica. Esta incapacidade de imaginar um evento com a magnitude da crise de 2007/2008, está também bem patente nas declarações dos gestores:

Não, não fiz teste ao marmoto seguido da onda de proporções bíblicas!... Não fiz! Não, não se fez o teste de "o cenário vai para zero"! Não, não se fez! Fizeram-se alguns testes: "Se a taxa abanar -1 , se subir +1 ", esses fizeram-se, mas para o cenário de zero, esse não se fez! Sr. Deputado, não se fez!! Mas [...] Sr. Deputado, eu também já expliquei porque é que não se fez! É porque em boa verdade, se houvesse esse convencimento não se teria feito nenhum contrato swap! Eu não o teria feito! Se em algum momento alguém avalizado [...] tivesse dito que em finais 2012 ou em 2013 a Euribor a 3 meses atingia 0,18 eu acho que não haveria provavelmente ninguém nesta sala que não lhe chamasse maluco. [...] Portanto, o que eu quero com isto é reforçar que esse cenário estava de todo fora das expectativas e da banda de intervalo. Foi só por isso que não foi...! Mas não foi! $!^{10}$

[...] cenários de Euribor a 0,2[\%] e de taxas a 10 anos a 0,80[\%] não foram, com certeza, contemplados. Mas não foram contemplados por nós, tal como não estavam contemplados por rigorosamente ninguém, porque eram absolutamente inimagináveis!11

Estas declarações confirmam o importante papel que as falhas da imaginação coletiva desempenharam no desenrolar da crise financeira (Bryan et al., 2012). A tentação de se obter mais informação para se lidar com níveis acrescidos de incerteza é ilusória. A situação de incerteza fundamental é irredutível, o que numa situação de crise provoca a sensação desconfortável de que a informação disponível é, ao mesmo tempo, demasiada para poder ser analisada com o detalhe necessário e insuficiente para proporcionar um nível aceitável de certeza nas decisões a tomar (Tuckett, 2011).

10 Ata da audição de 12/09/2013 ao Presidente do Conselho de Administração do Metropolitano de Lisboa (no período de novembro de 2006 a junho de 2010), pp. 119-120.

11 Ata da audição de 04/09/2013 ao Presidente da Carris e do Metropolitano de Lisboa (no período de 2003 a 2013), p. 76. 


\section{Ilusões cognitivas}

As atividades económicas não se desenvolvem no vácuo; pelo contrário, a sociologia económica tem mostrado que estas se revestem de uma natureza contingente em relação a diversos fatores, entre os quais se incluem as características cognitivas dos agentes (Zukin e DiMaggio, 1990). A inserção das decisões num enquadramento cognitivo (cognitive embeddedness) permite enfatizar os limites com que os atores sociais se confrontam no momento de efetuar escolhas. Neste sentido, a inserção cognitiva preocupa-se com as formas através das quais as regularidades estruturadas dos processos mentais limitam o exercício do raciocínio económico (ibidem). Ao longo do tempo tem sido observado por estudiosos das finanças comportamentais (e.g., Kahneman et al., 1982) e por especialistas em sociologia económica (e.g., Abolafia, 1996; Davis, 2006), que os atores económicos se socorrem de uma combinação de elementos metrológicos e não metrológicos nos seus processos de decisão. De entre esses elementos destacam-se diversas heurísticas decisionais de que os agentes fazem uso para efetuar escolhas em contexto de incerteza. Essas heurísticas, apesar de permitem aos agentes interpretar e dar um sentido aos dados disponíveis, podem conduzi-los a decisões erradas. Alguns autores estabelecem uma analogia entre a visão da realidade ditada por essas heurísticas e as ilusões de ótica (e.g., Kahneman, 2003).

É necessário notar ainda que os limites da racionalidade completa e o recurso às heurísticas decisionais levantam importantes implicações para o funcionamento dos mercados financeiros modernos. Autores como Keynes (1936) e Minsky (1986, 1992) abordam este assunto. Para Keynes (1936), a incerteza inerente aos mercados financeiros leva a que os investidores sejam influenciados por fatores psicológicos que os afastam das regras de decisão previstas pela racionalidade axiomática. Assim, os investidores encontram vantagens em decidir em função das suas expectativas quanto à atuação dos restantes investidores, ao invés de decidir com base na comparação entre os preços de mercado dos ativos financeiros e o valor atuarial desses ativos. As suas decisões acabam por traduzir-se, frequentemente, na adoção de comportamentos de imitação nos mercados financeiros e na preferência por detenção de uma maior liquidez como forma de lidar com a incerteza. Estas formas de atuação, por sua vez, acarretam a perda do valor informativo dos preços dos mercados financeiros que lhe é normalmente atribuído pelas correntes económicas de inspiração neoclássica. Para Minsky (1986, 1992), o excesso de confiança dos agentes - motivado por um bom desempenho da economia nos tempos recentes - leva-os a endividar-se de forma cada vez mais intensa. Este movimento é reforçado pela desvalorização, por parte 
dos investidores, dos efeitos potencialmente desestabilizadores da contração de dívida em excesso. O aumento dos preços decorrente do otimismo dos investidores contribui para sustentar, numa primeira fase, esse crescimento da dívida. No entanto, o crescimento "eufórico" da economia que daqui resulta não pode durar indefinidamente. A certo ponto, a incerteza revelará uma frustração das expectativas otimistas dos investidores e tornar-se-á evidente para a generalidade destes agentes que o futuro será bem diferente do esperado. Neste quadro, dar-se-á um aumento súbito da preferência por liquidez e uma tentativa de redução acelerada do endividamento por parte da generalidade dos agentes. Este movimento, por ocorrer num contexto económico onde as relações de endividamento são muito densas, tende a gerar dificuldades financeiras em muitos investidores. Daí resulta uma significativa instabilidade nos mercados de ativos financeiros.

A abordagem da componente cognitiva tem marcado vários estudos sociológicos nos últimos anos. Por exemplo, num estudo etnográfico ao mercado de obrigações, Abolafia (1998) conclui que as heurísticas decisionais constituem um dos principais instrumentos de que se socorrem os operadores de mercado na construção de uma "racionalidade local". Já Davis (2006) realça que aspetos psicológicos relacionados com a emoção, ambição e sentimento emergem constantemente nas entrevistas realizadas a gestores de investimento e analistas financeiros. De igual forma, Zaloom (2006) destaca a perceção dos agentes que operam em salas de mercados de que os incentivos económicos estão longe de serem suficientes para explicar a sua atração pelas transações financeiras. Estas envolvem elementos de excitação, descoberta e prazer tão intensos que alguns agentes os associam ao mesmo sentimento de se pertencer a uma claque de futebol. E MacKenzie (2006) mostra que as limitações cognitivas dos agentes (em termos de memória, capacidade de cálculo, etc.) são essenciais para se entender a importância que os meios materiais de cálculo representam no ambiente de decisão.

Mais próximo do caso em análise neste artigo, os aspetos cognitivos são também evidentes na relação que se estabelece entre os criadores de instrumentos financeiros (bancos) e os seus utilizadores. Ho (2009) e Lépinay (2011), na sequência de estudos etnográficos a bancos dos EUA e França, evidenciam a importância dos aspetos comportamentais na criação e negociação de instrumentos financeiros. Por um lado, Ho (2009) mostra que o excesso de confiança e um sentido de superioridade face a concorrentes e clientes são marcas da cultura de Wall Street. Por outro lado, Lépinay (2011) destaca os aspetos sociais que emergem da relação entre os atores na banca de investimento. Fatores como o instinto e a capacidade de reconhecer as tendências dos preços são considerados importantes nesse setor. 
E o networking e a busca de reconhecimento revelam-se pelo menos tão importantes como as componentes associadas a salários e prémios monetários.

Os estudos que acabámos de referir refletem a perspetiva dos agentes que criam os instrumentos financeiros e que os tentam vender aos seus clientes. No entanto, a perspetiva dos clientes está, em grande medida, ausente nesses estudos. A sociologia francesa do crédito, revista por Lacan e Lazarus (2015), constitui, no entanto, uma exceção que merece ser assinalada. Lépinay (2011) sugere que a incerteza inerente ao ambiente de negociação, combinada com a elevada complexidade dos contratos, permite às forças comerciais dos bancos moldar as preferências dos clientes. São reportadas histórias de clientes que contactaram os bancos para contratar instrumentos de cobertura de risco de um dado ativo e que acabaram, no final, por efetuar contratos sobre ativos substancialmente diferentes. No entanto, apesar destas evidências anedóticas, não é apresentada a perspetiva dos clientes relativa aos contratos assinados, nem a interpretação dos motivos que conduziram à contratação desses instrumentos.

O nosso objetivo neste artigo é o de contribuir para colmatar esta lacuna ao discutir as limitações cognitivas que, por transparecerem nas narrativas dos agentes que contrataram os swaps, é plausível admitir que foram relevantes no processo negocial e de decisão final. Ao fazê-lo, estamos a dar resposta ao apelo de Zajac e Westphal (2004) para que a psicologia cognitiva e a sociologia sejam utilizadas em conjunto para melhor se entender o comportamento dos atores de mercado.

$\mathrm{Na}$ presente secção recorreu-se a conceitos da psicologia cognitiva, sendo que no âmbito do trabalho de análise documental sobre esta temática procedeu-se à identificação dos principais enviesamentos cognitivos mencionados na literatura da área das finanças comportamentais, nomeadamente em Ackert e Deaves (2010) e em Lobão (2015). Depois, procuraram-se no discurso dos gestores as passagens que poderiam sinalizar a existência dos enviesamentos elencados. A análise do discurso dos compradores de swaps revela que a inserção cognitiva das suas decisões parece ter assumido uma importância capital. De facto, a partir dos seus discursos, podem ser detetados sinais de diversos enviesamentos decisionais, de entre os quais se destacam: o excesso de confiança, o enviesamento de representatividade, o enviesamento de disponibilidade e a aversão a perdas.

\subsection{Excesso de confiança}

O excesso de confiança pode ser definido como a convicção de que as capacidades próprias de decisão, raciocínio e demais aptidões são superiores 
ao que, na realidade, se verifica. Esta crença exagerada nas capacidades próprias afeta a generalidade dos atores sociais, de tal forma que DeBondt e Thaler (1995: 389) consideram que o excesso de confiança é "talvez a mais robusta evidência empírica na área da psicologia da decisão". Para se ter uma noção da prevalência deste enviesamento, pode-se referir que, numa pesquisa incidindo sobre mais de 2000 gestores empresariais, se concluiu que apenas menos de $1 \%$ não manifestava sintomas do excesso de confiança (Russo e Schoemaker, 1992).

$\mathrm{Na}$ tomada de decisão manifesta-se um excesso de confiança nas previsões, o que significa que os gestores pensam poder prever melhor o futuro do que na realidade fazem. Este efeito de subestimação da incerteza está bem claro nas declarações dos gestores no caso dos swaps, uma vez que confessam que os testes de stress quanto à evolução da taxa de juro se situaram num intervalo demasiado estreito, não considerando a possibilidade de ocorrência de valores extremos nessa variável:

[...] os riscos, naturalmente, existiam mas a probabilidade de ocorrência desses riscos era tão pequena, de facto, que não se justificava valorizá-los [....$^{12}$

$\mathrm{Na}$ altura, se calhar, nem valia a pena termos colocado essa opção, porque a probabilidade de as taxas descerem [...] abaixo dos tais $2 \%$ que estavam considerados como barreira inferior era absolutamente remota! Absolutamente remota!!13

As declarações sugerem que o excesso de confiança pode ter levado a que os gestores tivessem subestimado a probabilidade de ocorrência de uma variação das taxas de juro para além dos limites da banda de flutuação estabelecida no contrato swap. Tal ajuda a compreender que tenham sido aceites intervalos de variação demasiado estreitos para a evolução da taxa de juro.

Mas o excesso de confiança pode exercer igualmente os seus efeitos depois das decisões terem sido tomadas. É comum que os atores que evidenciam este enviesamento cognitivo subestimem a complexidade dos problemas com que se depararam (Glaser et al., 2013). A sobrestimação das capacidades técnicas dos gestores está bem patente na avaliação que fazem das suas próprias competências e dos contratos realizados:

\footnotetext{
${ }_{12}$ Ata da audição de 04/09/2013 ao Presidente da Carris e do Metropolitano de Lisboa (no período de 2003 a 2013), p. 94.

13 Ata da audição de 22/10/2013 ao 2. ${ }^{\circ}$ Diretor Administrativo e Financeiro da Metro do Porto (no período de julho de 2006 a junho de 2011), p. 98.
} 
No momento da negociação [...] estávamos convictos de que não podíamos ter melhor expertise para negociar do que aquela que tínhamos. Provavelmente, foi vaidade nossa... ${ }^{14}$

Parece-me que, em 2008, janeiro de 2008, não significa propriamente leviandade, significa conforto que todos nós tivemos de crédito em abundância, de mercado disponível para tudo [...] E isso foi, como eu há pouco dizia, vaidade pessoal de nós todos, se calhar, de alguns [...] Não me parece leviandade. Parece-me alguma... Olhe, direi, arrogância intelectual. ${ }^{15}$

Mesmo quando entidades independentes como o Instituto de Gestão do Crédito Público consideraram que os contratos realizados se revestiam de elevada complexidade, isso não parece ter sido reconhecido pelos gestores: "[b]om, complexidade: nenhuma! Ou se conhece uma operação swap e se conhece este swap ou não se conhece uma operação swap! Portanto, complexidade não há nenhuma!"16

\subsection{Enviesamento de representatividade}

A representatividade é um enviesamento cognitivo que se traduz na tendência para avaliar a probabilidade de um evento considerando o grau de semelhança desse evento com os dados disponíveis (Tversky e Kahneman, 1974).

O enviesamento é responsável pela percepção errada dos efeitos da dimensão da amostra. Os indivíduos tendem a interpretar os dados que têm à sua disposição como sendo representativos de toda a população, mesmo que a dimensão da amostra seja reduzida. Este efeito, conhecido também pela "lei dos pequenos números", pode levar a extrapolações precipitadas e a decisões erradas.

A "lei dos pequenos números" parece ter estado na origem da decisão de avaliar as possibilidades de variação da taxa de juro com base numa amostra demasiado pequena e, por isso, não inteiramente representativa do risco inerente à contratação dos swaps. Uma das empresas públicas, por exemplo, utilizou uma amostra de apenas oito anos de dados históricos da taxa Euribor para decidir acerca da contratação de um swap cujos efeitos

\footnotetext{
14 Ata da audição de 10/09/2013 ao Presidente do Conselho de Administração da Metro do Porto (no período de março de 2008 a julho de 2012), p. 84.

15 Ata da audição de 10/09/2013 ao Presidente do Conselho de Administração da Metro do Porto (no período de março de 2008 a julho de 2012), p. 89.

${ }_{16}$ Ata da audição de 16/09/2013 ao Presidente da Estradas de Portugal (no período de novembro de 2007 a março de 2011), p. 36.
} 
se fariam sentir por um período de 14 anos e meio. Uma outra empresa usou uma amostra de apenas 10 anos de dados para decidir acerca de um instrumento financeiro com uma maturidade de 20 anos. Ao selecionar-se uma amostra demasiado curta - e ainda para mais caracterizada por uma relativa estabilidade dos valores da taxa de juro em termos históricos produziu-se uma subestimação quanto às possibilidades de evolução das variáveis no futuro.

Para além deste efeito, a perceção errada dos efeitos da dimensão da amostra pode levar os investidores a cometer erros na avaliação dos preços de mercado. $\mathrm{O}$ enviesamento da representatividade pode fazer com que se atribua demasiada importância às tendências de mercado mais recentes julgando-se (erradamente) que essas tendências persistirão no tempo (Benartzi, 2001).

A extrapolação que os gestores das empresas públicas parecem ter levado a efeito a partir da evolução das taxas de juro no passado recente revela-se em declarações como: "[u]ma vez que, de todas as análises então feitas, a perspetiva que havia era a de que, face à subida acentuada da taxa de juro [desde o início de 2004], haveria uma acentuação dessa subida durante algum tempo $[\ldots]$ ". ${ }^{17}$ Declarações deste teor sugerem que essa subida das taxas de juro criou a expectativa de uma continuação dessa tendência. E foi essa expectativa que suportou a decisão de contratação dos contratos de swaps.

\subsection{Enviesamento de disponibilidade}

O enviesamento de disponibilidade manifesta-se quando os indivíduos atribuem demasiada importância às informações que estão mais disponíveis em termos cognitivos, por serem por exemplo mais fáceis de recordar. Quando são chamados a realizar estimativas acerca da probabilidade de ocorrência de um evento, os indivíduos são influenciados, inconscientemente, pela facilidade com que as informações utilizadas para levar a cabo a tarefa lhes surgem à mente. $O$ facto de poder não existir uma coincidência entre a disponibilidade cognitiva das informações e a sua importância relativa, pode enviesar a importância atribuída à informação (Tversky e Kahneman, 1974).

O facto de os gestores das empresas públicas terem subestimado a probabilidade de ocorrência de um movimento extremo nas taxas de juro é consistente com o enviesamento da disponibilidade, na medida em que

17 Ata da audição de 05/09/2013 à Presidente da STCP (no período de abril de 2006 a junho de 2012), p. 19. 
eventos dessa natureza não tinham ocorrido nos tempos mais recentes e, por esse motivo, encontravam-se pouco disponíveis em termos cognitivos:

[...] àquela data, todos os dados disponíveis, quer os históricos, quer as previsões que eram feitas e que também estavam disponíveis - não inventamos nenhumas especiais -, não apontavam... [para um cenário de concretização dos riscos assumidos]. ${ }^{18}$

E o momento de mercado era: taxas de juro a subir - um histórico de taxas de juro que era perfeitamente conhecido. ${ }^{19}$

Conforme conclui Abolafia (1998), no universo dos investidores em obrigações, os preços mais recentes constituem uma das mais importantes fontes de informação para se estabelecer o valor dos ativos. Existem sinais de que tal ocorreu igualmente no mercado de contratos de swaps. O facto de os atores sociais disporem de uma memória histórica curta torna-os demasiado dependentes da informação mais recente e leva-os a subestimar as possibilidades de ocorrência de uma crise de elevada dimensão.

\subsection{Aversão a perdas}

A aversão a perdas traduz-se no facto de que a insatisfação que resulta de uma perda é normalmente superior à satisfação que os indivíduos retiram de um ganho esquivalente. Este comportamento é justificado pela Teoria da Perspetiva (Kahneman e Tversky, 1979) e produz a tendência de os decisores se tornarem propensos ao risco quando confrontados com alternativas que implicam a assunção de perdas.

A aversão a perdas, que se manifesta no discurso de alguns dos gestores de empresas públicas que contrataram swaps, pode ter estado na origem da relutância desses agentes em assumir as perdas ocorridas, reestruturando os swaps em que estas se estavam a verificar. É isso que parece transparecer no discurso de alguns dos gestores:

[E]ra preciso ver qual era contrapartida para se cancelar essa operação [de swaps]. Era o pagamento de larguíssimas dezenas de milhões de euros. ${ }^{20}$

\footnotetext{
${ }_{18}$ Ata da audição de 05/09/2013 à Presidente da STCP (no período de abril de 2006 a junho de 2012), p. 30.

19 Ata da audição de 22/10/2013 ao 2. ${ }^{\circ}$ Diretor Administrativo e Financeiro da Metro do Porto (no período de julho de 2006 a junho de 2011), p. 47.

${ }^{20}$ Ata da audição de 22/10/2013 ao 2. ${ }^{\circ}$ Diretor Administrativo e Financeiro da Metro do Porto (no período de julho de 2006 a junho de 2011), p. 65.
} 
[...] fiz a análise de que não me parecia apropriado, naquela altura, a empresa incorrer em mais riscos, cristalizar uma perda e aumentar os riscos [...]. Por causa de uma situação não estar, momentaneamente, a correr bem, não poderíamos aumentar ainda mais o risco da empresa. E foi isso que foi feito, foram recusadas as propostas de reestruturação. ${ }^{21}$

Os gestores, perante a necessidade de aceitação de perdas, parecem ter-se tornado propensos ao risco. Assim, das declarações depreende-se que os gestores se recusaram a aceitar as propostas de reestruturação das operações financeiras uma vez que estas implicariam o reconhecimento de perdas significativas com as operações contratadas. $\mathrm{O}$ que os gestores parecem subestimar, no entanto, é que a decisão de manter abertas operações de swaps que registavam perdas implicava a assunção de um risco: o risco de as perdas potenciais aumentarem. Este comportamento é consistente com o fenómeno de aversão a perdas descrito na literatura.

\section{Conclusão}

A crise financeira de 2007/2008 constitui uma excelente oportunidade para reexaminar o papel dos fatores sociais, políticos e económicos na decisão dos atores organizacionais. Neste artigo debatemos as marcas que as relações de poder, o ambiente de incerteza e as ilusões cognitivas deixaram transparecer no discurso dos gestores de empresas públicas portuguesas que contrataram swaps.

A análise levada a cabo permite perceber que uma realidade, que à primeira vista poderia parecer racional e ditada por fatores meramente técnicos, é afinal construída por um discurso modelado pelos contextos político, social e cultural em que se movem os atores organizacionais. Os mercados financeiros são um terreno povoado de valores humanos, de emoções e de normas institucionais. E é através da construção de narrativas quanto ao passado que os gestores controlam as suas próprias representações - presentes e futuras.

As relações de poder e a coação são inevitáveis numa sociedade complexa; não existe a possibilidade de os agentes escaparem à responsabilidade de escolher entre alternativas. Vimos que a transação de instrumentos derivados, como os contratos de swaps, se opera sob o signo da assimetria informacional e que o seu sucesso depende, de forma crítica, da ausência de reciprocidade entre as partes.

${ }^{21}$ Ata da audição de 05/09/2013 à Presidente da STCP (no período de abril de 2006 a junho de 2012), p. 27. 
A perceção de que os mercados financeiros são um campo social em que grupos de atores individuais e coletivos se mantêm juntos pelo problema da incerteza é essencial para perceber as suas decisões. Aceitar que os agentes tomem decisões num contexto de incerteza coloca em evidência o papel que as circunstâncias históricas e as ilusões cognitivas desempenham no momento da escolha de alternativas. De facto, os atores sociais têm uma perspetiva enviesada da realidade de que não podem escapar, tenham ou não consciência disso.

As esferas social, psicológica e política não estão separadas da esfera da economia. Pelo contrário, essas perspetivas interpenetram-se e modelam-se mutuamente. A atividade económica é marcada pelas limitações cognitivas dos atores sociais, pela cultura, por padrões e normativos societais e por relações de autoridade. Este entendimento abre espaço à intervenção dos poderes públicos. Os mercados têm que ser criados e as políticas públicas podem influenciar a forma e a natureza das instituições económicas, num ambiente em que os atores exercem o seu poder procurando influenciar a distribuição de recursos naturalmente limitados.

O que a complexidade das economias modernas exige cada vez mais é uma análise mais contextualizada que, em lugar de uma visão irrealista do que é o "homem económico", adote uma sociologia do homem real, que tenha em conta o conjunto de ligações que constitui o ser social e a sua humanidade. O significado das decisões é construído historicamente, pelo que se requer uma investigação empírica das circunstâncias destas - ao invés de esse significado ser simplesmente assumido a partir de pressupostos mais ou menos arbitrários. Um estudo multifacetado dos mercados financeiros enquanto teias de interações sociais pode contribuir para um melhor entendimento da posição e do papel destes no seio das sociedades, um papel que vai muito para além da afetação de recursos escassos e do processamento de incertezas económicas. Este artigo, julgamos nós, constitui mais um passo para que se caminhe nesse sentido.

Levamos a cabo neste trabalho uma análise sociopsicológica das declarações prestadas pelos gestores das empresas públicas que contrataram swaps. As estratégias discursivas dos outros agentes em confronto (Estado enquanto acionista, entidades bancárias) não foram exploradas. Uma linha de investigação futura nesta temática poderá passar pela consideração do discurso destas entidades.

Revisto por Ana Sofia Veloso 


\section{Referências bibliográficas}

Abolafia, Mitchel Y. (1996), Making Markets: Opportunism and Restraint on Wall Street. Cambridge, MA: Harvard University Press.

Abolafia, Mitchel Y. (1998), "Markets as Cultures: An Ethnographic Approach", Sociological Review, 46, 69-85.

Abolafia, Mitchel Y. (2005), "Making Sense of Recession: Policy Making at the Federal Reserve", in Victor Nee; Richard Swedberg (orgs.), The Economic Sociology of Capitalism. Princeton, NJ: Princeton University Press, 204-226.

Ackert, Lucy F.; Deaves, Richard (2010), Behavioral Finance: Psychology, Decision-Making, and Markets. Mason, $\mathrm{OH}$ : South-Western Cengage Learning.

Ailon, Galit (2012), "The Discursive Management of Financial Risk Scandals: The Case of Wall Street Journal Commentaries on LTCM and Enron”, Qualitative Sociology, 35, 251-270.

Arnoldi, Jakob (2004), "Derivatives: Virtual Values and Real Risks", Theory, Culture \& Society, 21, 23-42.

Baum, Joel A. C.; Oliver, Christine (1992), "Institutional Embeddedness and the Dynamics of Organizational Populations”, American Sociological Review, 57, 540-559.

Beckert, Jens (1996), "What Is Sociological about Economic Sociology? Uncertainty and the Embeddedness of Economic Action”, Theory \& Society, 25, 803-840.

Benartzi, Shlomo (2001), "Excessive Extrapolation and the Allocation of 401(k) Accounts to Company Stocks", Journal of Finance, 56, 1747-1764.

Bryan, Dick; Martin, Randy; Montgomerie, Johnna; Williams, Karel (2012), “An Important Failure: Knowledge Limits and the Financial Crisis”, Economy and Society, 41, 299-315.

Carruthers, Bruce G. (1996), City of Capital: Politics and Markets in the English Financial Revolution. Princeton, NJ: Princeton University Press.

Carruthers, Bruce G.; Kim, Jeong-Chul (2011), “The Sociology of Finance”, Annual Review of Sociology, 37, 239-259.

Davis, Aeron (2006), "The Limits of Metrological Performativity: Valuing Equities in the London Stock Exchange”, Competition \& Change, 10, 3-21.

DeBondt, Werner; Thaler, Richard (1995), "Financial Decision-Making in Markets and Firms: A Behavioral Perspective", in Robert Jarrow; Vojislav Maksimovic; William Ziemba (orgs.), Finance: Handbooks in Operations Research and Management Science, vol. 9. Amsterdam: North Holland, 385-410.

Devlin, Michael; Lucey, Brian (2016), "Is Executive Hubris Manifested in CEO Letters to Shareholders?", Social Science Research Network. Consultado a 17.07.2020, em https://ssrn.com/abstract=2833919.

Dow, Sheila C. (2012), "Uncertainty about Uncertainty", in Sheila C. Dow (org.), Foundations for New Economic Thinking: A Collection of Essays. London: Palgrave Macmillan. 
Dunn, Stephen P. (2001), "Bounded Rationality Is Not Fundamental Uncertainty: A Post Keynesian Perspective”, Journal of Post Keynesian Economics, 23, 567-587. Glaser, Markus; Langer, Thomas; Weber, Martin (2013), "True Overconfidence in Interval Estimates: Evidence Based on a New Measure of Miscalibration”, Journal of Behavioral Decision Making, 26, 405-417.

Hasbani, Marc; Breton, Gaétan (2013), "Restoring Social Legitimacy: Discursive Strategies Used by a Pharmaceutical Industry Leader", Society and Business Review, 8, 71-89.

Ho, Karen (2009), Liquidated: An Ethnography of Wall Street. Durham, NC: Duke University Press.

Holmes, Douglas (2009), "Economy of Words”, Cultural Antbropology, 24, 381-419.

Kahneman, Daniel (2003), "Maps of Bounded Rationality: Psychology for Behavioral Economics”, American Economic Review, 93, 1449-1475.

Kahneman, Daniel; Tversky, Amos (1979), "Prospect Theory: An Analysis of Decision under Risk”, Econometrica, 47, 263-292.

Kahneman, Daniel; Slovic, Paul; Tversky, Amos (orgs.) (1982), Judgment under Uncertainty, Heuristics and Biases. Cambridge, MA: Cambridge University Press.

Keynes, John Maynard (1936), The General Theory of Employment, Interest and Money. London: MacMillan.

Lacan, Laure; Lazarus, Jeanne (2015), “A Relationship and a Practice: On the French Sociology of Credit”, Maxpo Discussion Paper, 15(1). Consultado a 22.06.2020, em http://www.maxpo.eu/pub/maxpo_dp/maxpodp15-1.pdf.

Lépinay, Vincent Antonin (2011), Codes of Finance: Engineering Derivatives in a Global Bank. Princeton, MA: Princeton University Press.

Lobão, Júlio (2015), Finanças Comportamentais: quando a Economia encontra a Psicologia. Coimbra: Actual Editora.

MacKenzie, Donald (2006), An Engine, Not a Camera: How Financial Models Shape Markets. Cambridge, MA: MIT Press.

McCloskey, Deirdre N. (1992), “The Rhetoric of Finance”, in Murray Milgate, Peter Newman; John Eatwell (orgs.), The New Palgrave Dictionary of Money and Finance. London: Macmillan Press, 350-352.

Mcguire, Patrick; Granovetter, Mark (1999), "Shifting Boundaries and Social Construction in the Early Electricity Industry, 1878-1910”, in Marc Ventresca; Joseph Porac (orgs.), Constructing Industries and Markets. London: Elsevier Science.

Minsky, Hyman (1986), Stabilizing an Unstable Economy. New Haven, CT: Yale University Press.

Minsky, Hyman (1992), “The Financial Instability Hypothesis”, Levy Economics Institute Working Paper, 74.

Pistor, Katharina (2013), “A Legal Theory of Finance”, Journal of Comparative Economics, 41, 315-330. 
Pixley, Jocelyn (2014), “Uncertainty: The Curate’s Egg in Financial Economics”, British Journal of Sociology, 65, 200-224.

Rosenhek, Zeev (2013), "Diagnosing and Explaining the Global Financial Crisis: Central Banks, Epistemic Authority, and Sense Making”, International Journal of Politics, Culture, and Society, 26, 255-272.

Russo, J. Edward; Schoemaker, Paul J. H. (1992), "Managing Overconfidence”, Sloan Management Review, 33, 7-18.

Smeltzer, Neil; Swedberg, Richard (2005), "Introducing Economic Sociology”, in Neil Smeltzer; Richard Swedberg (orgs.), The Handbook of Economic Sociology. Princeton, NJ: Princeton University Press, 3-25.

Svetlova, Ekaterina (2012), "Talking about the Crisis: Performance of Forecasting in Financial Markets”, 18, 155-169.

Swedberg, Richard (2010), "The Role of Confidence in Finance”, in Karen Knorr Cetina; Alex Preda (orgs.), The Handbook of the Sociology of Finance. Oxford: Oxford University Press, 529-545.

Taleb, Nassim (2010), The Black Swan: The Impact of the Highly Improbable. New York: Random House.

Tuckett, David (2011), Minding the Markets: An Emotional Finance View of Financial Instability. London: Palgrave Macmillan.

Tversky, Amos; Kahneman, Daniel (1974), "Judgment under Uncertainty: Heuristics and Biases", Science, 185, 1124-1131.

Zajac, Edward J.; Westphal, James D. (2004), “The Social Construction of Market Value: Institutionalization and Learning Perspectives on Stock Market Reactions", American Sociological Review, 69, 433-457.

Zaloom, Caitlin (2006), Out of the Pits: Traders and Technology from Chicago to London. Chicago, IL: University of Chicago Press.

Zukin, Sharon; DiMaggio, Paul (orgs.) (1990), Structures of Capital: The Social Organization of the Economy. Cambridge, MA: Cambridge University Press.

Artigo recebido a 17.09.2019

Aprovado para publicação a 26.06.2020

\section{Júlio Lobão}

Faculdade de Economia da Universidade do Porto Rua Dr. Roberto Frias, 4200-464 Porto, Portugal

Contacto: jlobao@fep.up.pt ORCID: https://orcid.org/0000-0001-5896-9648 


\section{Swaps and State-Owned Enterprises in Portugal: A Story of Power, Black Swans and Illusions}

The building of narratives is one of the central elements in the functioning of modern financial markets. In this paper we analyze the discursive strategies of a group of managers of state-owned enterprises operating in Portugal prior to the creation of that country's parliamentary committee of inquiry (CPI). This committee was established in 2013 by the Assembly of the Republic to investigate the losses resulting from the use of derivative contracts (swaps) in state-owned enterprises. Using concepts from several scientific fields including Sociology of Finance and Cognitive Psychology, our analysis reveals that uncertainty and the managers' cognitive illusions influenced their narratives of rationalization. The power relations between the relevant social actors (public authorities, banks, firms) are also evident in the managers' discourse. In our conclusions we highlight the implications of these factors for the construction of a more contextualized view of financial relationships. Keywords: business management; financial markets; Portugal; power relations; state-owned enterprises; uncertainty (economy).

\section{Swaps et entreprises publiques au Portugal: une histoire de pouvoir, cygnes noirs et illusions}

La construction de récits est un des éléments centraux du fonctionnement des marchés financiers modernes. Dans cet article, on analyse les stratégies discursives d'un groupe de dirigeants d'entreprises publiques au Portugal devant une commission d'enquête parlementaire. Cette commission a été créée par l'Assemblée de la République en 2013 pour enquêter sur les pertes générées par le recours à la célébration de contrats dérivés (swaps) par des entreprises publiques. En utilisant des concepts de plusieurs domaines scientifiques tels que la sociologie de la finance et la psychologie cognitive, l'analyse révèle que les conditions d'incertitude et les illusions cognitives des dirigeants ont influencé leurs récits de rationalisation. Les relations de pouvoir entre les acteurs sociaux présents (autorités publiques, banques, entreprises) se reflètent également dans le discours des dirigeants. Les conclusions soulignent les implications de ces facteurs pour la construction d'une vision plus contextualisée des relations financières.

Mots-clés: entreprises publiques; gestion d'entreprise; incertitude (économie); marchés financiers; Portugal; relations de pouvoir. 